Supplement of Atmos. Chem. Phys., 16, 9421-9433, 2016

http://www.atmos-chem-phys.net/16/9421/2016/

doi:10.5194/acp-16-9421-2016-supplement

(C) Author(s) 2016. CC Attribution 3.0 License.

(c) (i)

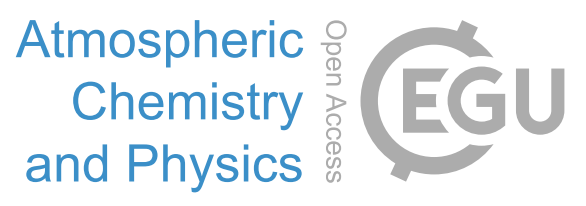

Supplement of

\title{
Conditions for super-adiabatic droplet growth after entrainment mixing
}

Fan Yang et al.

Correspondence to: Raymond Shaw (rashaw@mtu.edu)

The copyright of individual parts of the supplement might differ from the CC-BY 3.0 licence. 
Table S1: Initial dry aerosol radii for different bins.

\begin{tabular}{|c|c|c|c|}
\hline Bin number & $\mathrm{r}_{\text {dry }}(\mathrm{nm})$ & Bin number & $\mathrm{r}_{\text {day }}(\mathrm{nm})$ \\
\hline 1 & 463.7 & 11 & 61.5 \\
\hline 2 & 378.9 & 12 & 50.3 \\
\hline 3 & 309.6 & 13 & 41.1 \\
\hline 4 & 253.0 & 14 & 33.6 \\
\hline 5 & 206.7 & 15 & 27.4 \\
\hline 6 & 168.9 & 16 & 22.4 \\
\hline 7 & 138.0 & 17 & 18.3 \\
\hline 8 & 112.8 & 18 & 15.0 \\
\hline 9 & 92.1 & 19 & 12.2 \\
\hline 10 & 75.3 & 20 & 10.0 \\
\hline
\end{tabular}



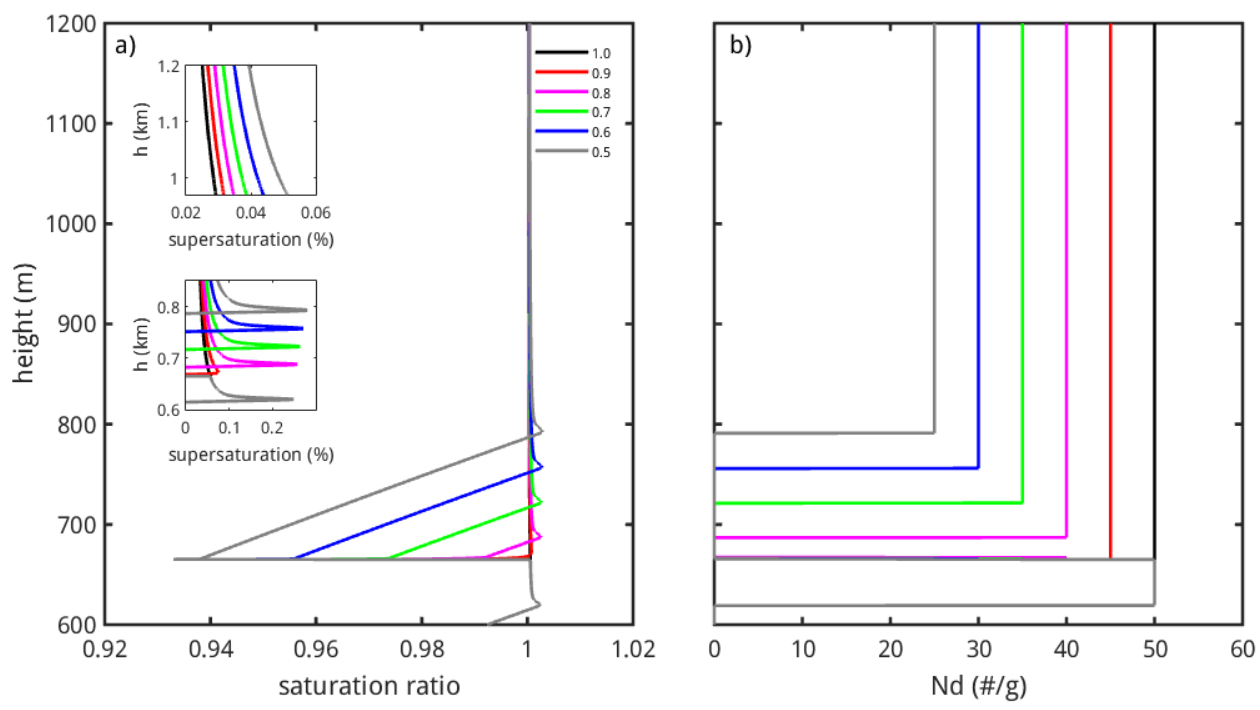

Figure S1: (a) Saturation ratio and (b) cloud droplet number concentration profiles for various cloud mixing fractions when monodisperse cloud droplets mix with clean environment air with low updraft velocity $\left(0.1 \mathrm{~ms}^{-1}\right)$.
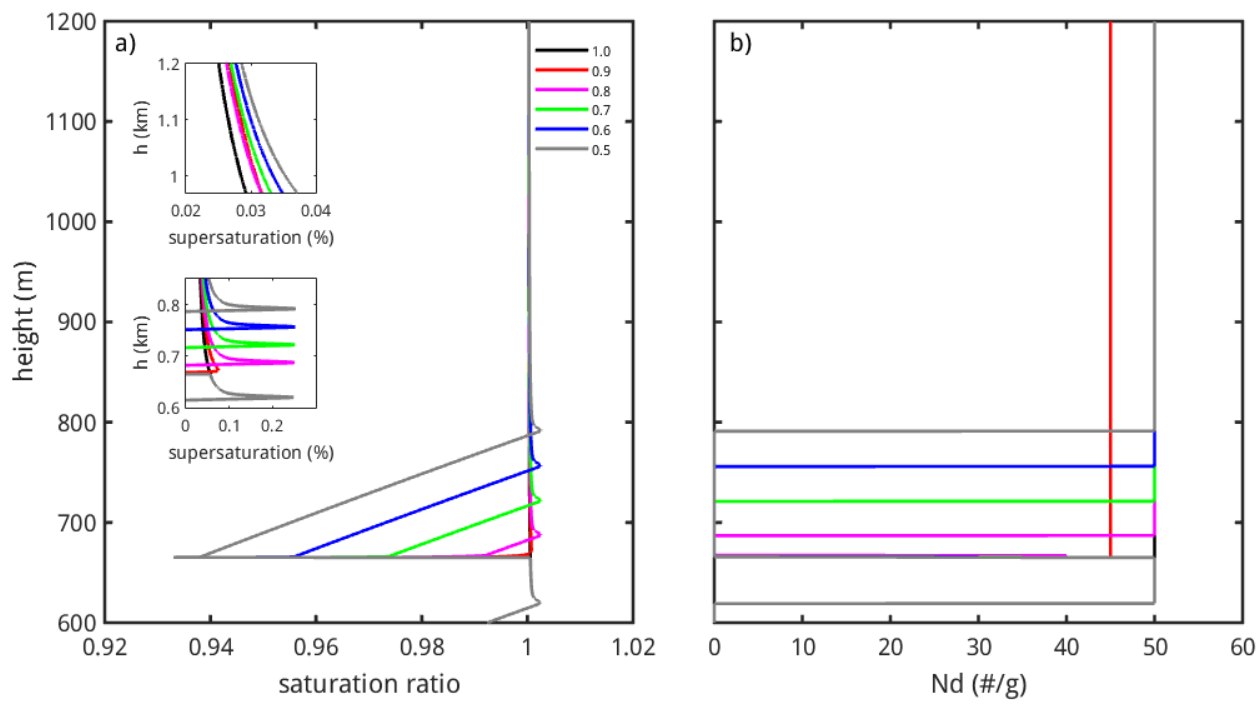

Figure S2: (a) Saturation ratio and (b) cloud droplet number concentration profiles for various cloud mixing fractions when monodisperse cloud droplets mix with polluted environment air with low updraft velocity $\left(0.1 \mathrm{~ms}^{-1}\right)$. 

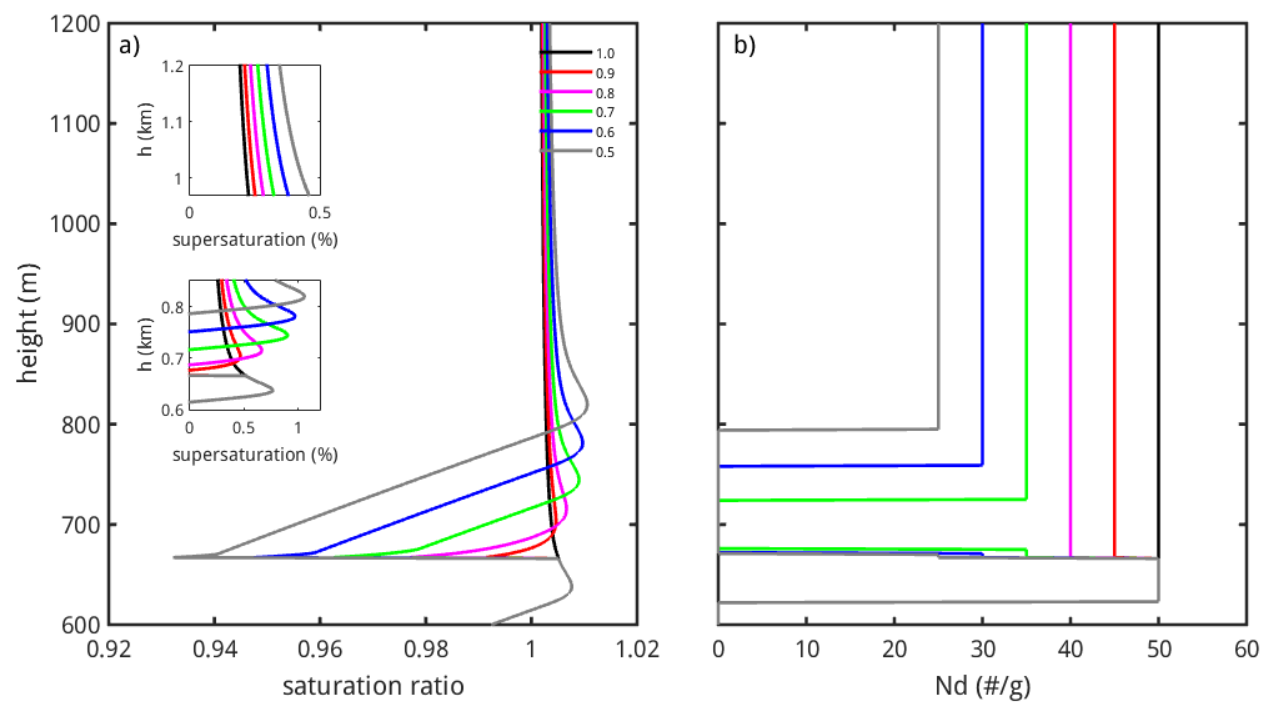

Figure S3: (a) Saturation ratio and (b) cloud droplet number concentration profiles for various cloud mixing fractions when monodisperse cloud droplets mix with clean environment air with high updraft velocity $\left(1.0 \mathrm{~ms}^{-1}\right)$.
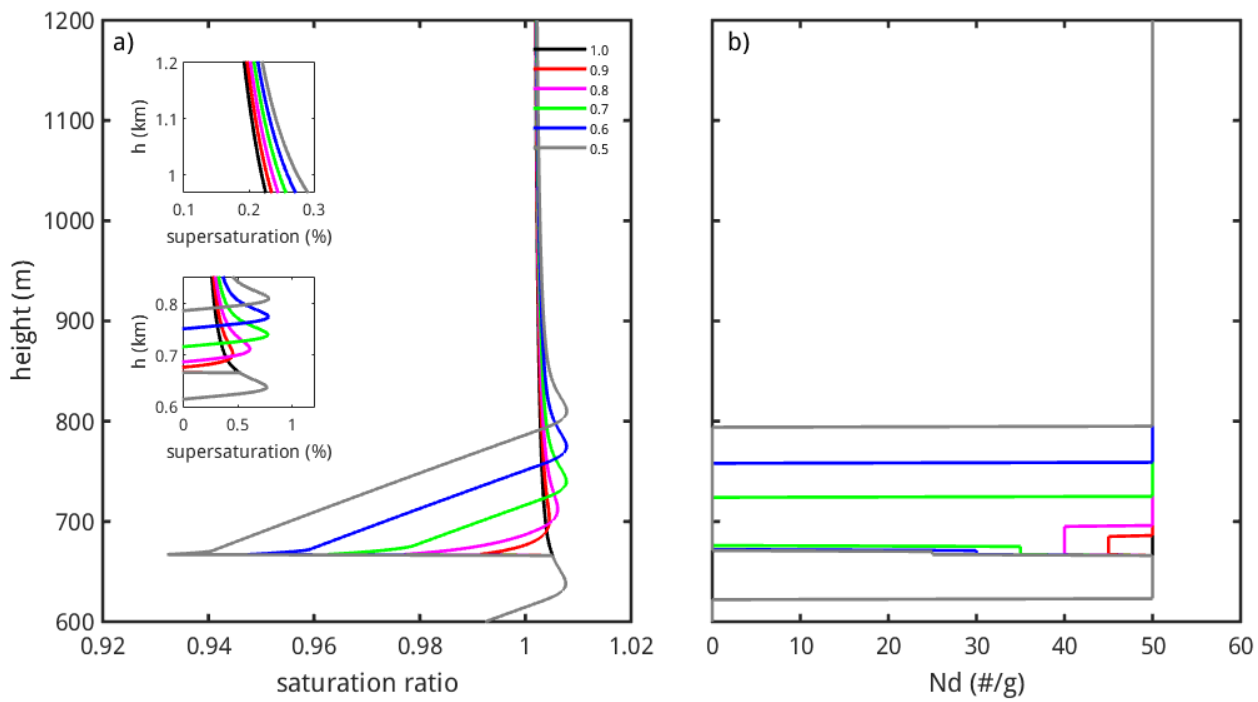

Figure S4: (a) Saturation ratio and (b) cloud droplet number concentration profiles for various cloud mixing fractions when monodisperse cloud droplets mix with polluted environment air with high updraft velocity $\left(1.0 \mathrm{~ms}^{-1}\right)$. 

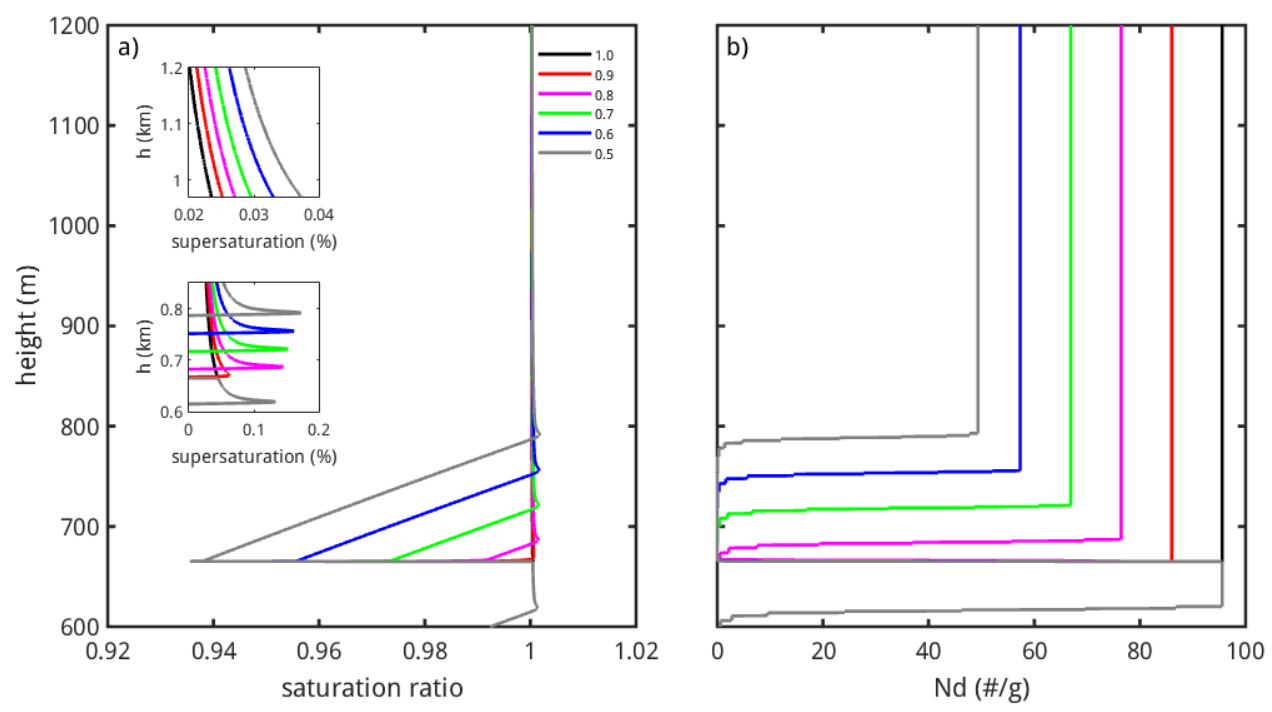

Figure S5: (a) Saturation ratio and (b) cloud droplet number concentration profiles for various cloud mixing fractions when polydisperse cloud droplets mix with clean environment air with low updraft velocity $\left(0.1 \mathrm{~ms}^{-1}\right)$.
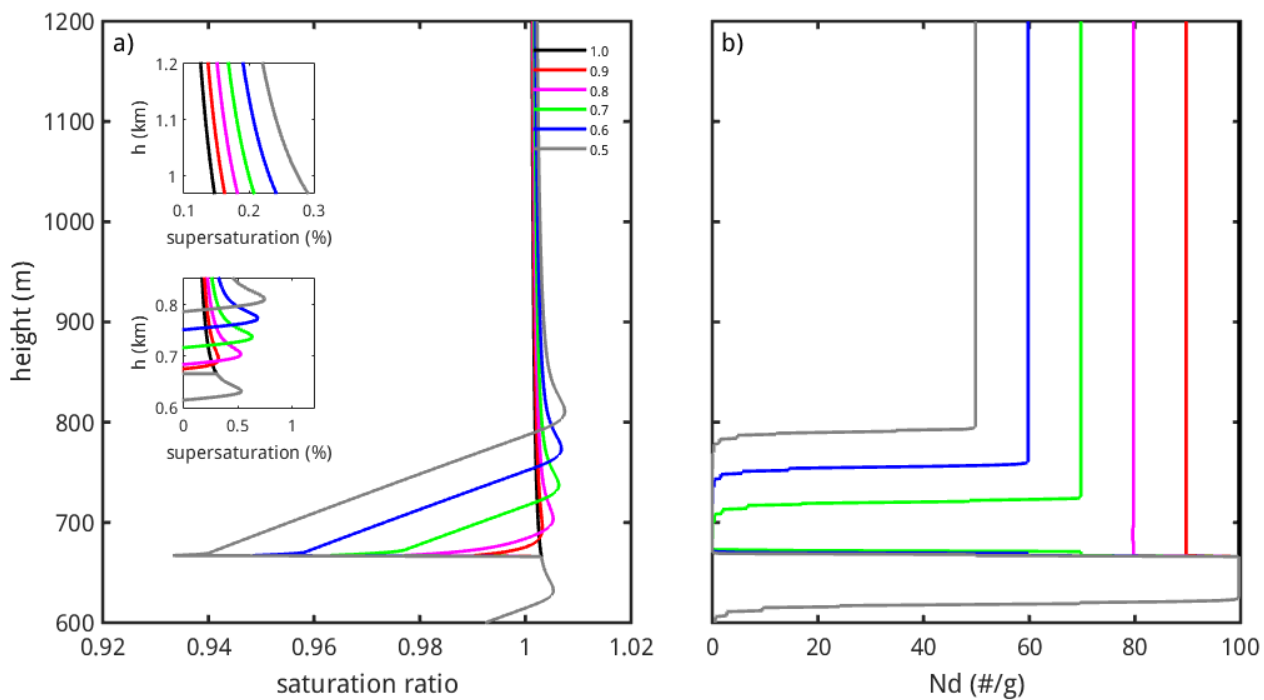

Figure S6: (a) Saturation ratio and (b) cloud droplet number concentration profiles for various cloud mixing fractions when polydisperse cloud droplets mix with clean environment air with high updraft velocity $\left(1.0 \mathrm{~ms}^{-1}\right)$. 